\title{
Assessing users' experience of shared sanitation facilities: A case study of community ablution blocks in Durban, South Africa
}

\author{
Elisa Roma ${ }^{1}$, Chris Buckley ${ }^{2}$, Bruce Jefferson ${ }^{1}$ and Paul Jeffrey ${ }^{1 *}$ \\ ${ }^{1}$ Centre for Water Science, Cranfield University, Cranfield, MK430AL, United Kingdom \\ ${ }^{2}$ Pollution Research Group, University of KwaZulu-Natal, Durban 4041, South Africa
}

\begin{abstract}
Despite significant financial investment, the effective implementation and sustained use of water and sanitation (WATSAN) technologies remains a chimera, with one billion people using unimproved water facilities and two and a half billion not benefitting from adequate sanitation. The poor success rate of WATSAN interventions results from a predominance of supply-driven approaches which lack recipients' inputs into planning and implementation to ensure that technologies are fully absorbed and adapted to users' needs. In the academic literature, users' feedback and experiences of technologies in the post-implementation phase have received scarce attention. The purpose of this study is to investigate users' experience of sanitation technologies in the early post-implementation phase, when opportunities for remedial intervention are still available. Fieldwork comprising semi-structured interviews was undertaken with users and potential recipients of three community ablution blocks (CABs) in informal settlements around Durban. Results suggest that non-technical aspects such as affordability or cleanliness of the facilities can affect acceptance among the investigated communities. User training is positively associated with higher levels of facility maintenance as well as satisfaction with its functionality. A comparison between users and potential recipients of CABs shows that perceived health benefits, attitudes in case of problems, and trust are affected by use of the facilities. Conclusions relate to how early post-implementation assessments of users' experience could enhance the process of acceptance and management of the technology, thereby increasing progress towards achievement of the related Millenium Development Goals.
\end{abstract}

Keywords: Ablution blocks, user acceptance, eThekwini municipality, Durban, sanitation

\section{Introduction}

The most recent UN Joint Monitoring Programme report suggests that achievement of the Millennium Development Goals (MDGs) for water and sanitation remains a chimera, with one billion people still using unimproved water facilities and two and a half billion not benefitting from improved sanitation. Progress on both targets is slowest in Sub-Saharan Africa (WHO and UNICEF, 2008). Recent years have witnessed the launch of several initiatives to alleviate the problem of inadequate water supply and sanitation services, by investing in the transfer of appropriate technologies. However, despite the financial resources and institutional commitment involved, most programmes have failed to deliver the expected benefits (Younger, 2007; Rodgers et al., 2007). Typically, unsuccessful interventions have been characterised by top-down approaches to service delivery with little consideration of recipients' demands or their participation in the planning, construction and implementation process (Breslin, 2004; Burra et al., 2003).

In the post-implementation stage of technology transfer, analyses of poor success rates of water and sanitation (WATSAN) projects focus mainly on the engineering aspects of the process, attributing lack of success to intrinsic technical faults and failings (Lübken et al., 2007). Alternative diagnoses which address the social and human aspects of technology transfer can be traced back to the work of Linstone (1981) and his conceptualisation of

\footnotetext{
* To whom all correspondence should be addressed.

III +44 (0)1234 754814; fax: +44 (0)1234 751671; e-mail: p.j.jeffrey@,cranfield.ac.uk

Received 29 October 2009; accepted in revised form 3 September 2010.
}

technologies as multi-perspective entities: possessing not only technical aspects, but also a set of organisational and personal dynamics in which the system is embedded. In the context of WATSAN initiatives in developing countries, few contributions have focused on the post-implementation phase of technology transfer, or investigated the reasons why users' desire or willingness to adopt has not translated into appropriately encouraging impacts (e.g. Simms et al., 2005; Mukheli et al., 2002). Findings from these studies attribute project failure to scarce attention to 'software' aspects in the implementation, such as lack of users' participation and capacity building (Burra et al., 2003) or their perceptions of ease and convenience of using the technology (Diallo et al., 2007). Although addressing human aspects of the transferred technology, these contributions provide evaluations of WATSAN technologies which are not guided by strong theoretical foundations and are conducted several months or years after implementation took place (Simms et al., 2005; Mukheli et al., 2002). The consequential lack of a constructive time frame for remedial action makes it difficult to establish accountability and to plan interventions.

In this study we respond to these weaknesses, by exploring and assessing the experience of community ablution block (CAB) users in informal settlements around Durban, where WATSAN provision is due to expand over the coming years to provide services to 317 new settlements. The investigation rests on the perspectives developed by Linstone (1981) as well as on the theoretical framework provided by the work on Receptivity, whereby the success of an implemented technology can be measured by investigating users' willingness and (crucially for this study) their ability to 'absorb, accept and utilise innovation options' (Jeffrey and Seaton, 2004: 281-282). The main 
premise behind the Receptivity model is the benefits to be gained from understanding the people's responses to a technology, in terms of perceptions, attitudes and agendas for change which are relevant to them. The Receptivity framework allows researchers to explore technology users' perceptions of problems related to water and sanitation and their ability to scan for new knowledge (Awareness); their understanding of the potentiality of knowledge exploitation and its association with needs and capabilities (Association); the process of learning to gain the knowledge and skills necessary to adopt a technology (Acquisition); and their ability of internalising it in their routine, organising maintenance and managing risk (Application).

The importance of Receptivity to the conduct of this research rests on its focus on feedbacks from CAB users by directing attention to those aspects of their experiences that influence acceptance of the facilities and thus their sustained use. The analysis of the research findings identifies potential challenges in technology implementation and suggests solutions, based on users' involvement, which increase a sense of ownership and acceptance of the technology. The timing of this investigation is opportune to provide an agenda for change, as Durban local government is expanding its provision of shared sanitation to the city's informal settlements.

\section{Urban sanitation in South Africa}

As a middle-income developing country, South Africa suffers unequal income distribution, with $34 \%$ of its population living below the poverty line (UN, 2005). This discrepancy is primarily reflected in the provision of basic services, such as water and sanitation, which are inadequate in informal settlements, characterised by high density of inhabitants, a largely transient population and poor health conditions.

South Africa has committed to meet MDGs Target 10 on increasing improved water and sanitation access by the year 2014. The efforts to expand coverage began after the apartheid era (1948-1994) through a more democratic redistribution of essential services according to principles of equity and dignity (Eales, 2008). With recognition of water scarcity and unequal resource distribution in the country, the Water Services Act of 1997 and National Water Act of 1998 established the right of all citizens to free water and basic sanitation as part of a strategy to fight poverty, whilst the new South African Constitution of 1996 transferred to local governments the responsibility for WATSAN service provision.

Besides reinstating the controversial debate on the nature of water as a public good, the principle of free water and sanitation bears important implications for WATSAN provision. Service delivery is thereby driven by supply-side approaches to achieve high coverage rates, a strategy which is often to the detriment of user engagement (Kihato and Schmidt, 2002). Although demand-driven and community-based approaches to water and sanitation interventions are recognised by South African WATSAN policies (DWAF, 1994), enthusiasm for participation does not often materialise in practice (Friedman, 2006). As reported in previous research on service delivery, users' agendas are not always transferred in consultative processes where feedbacks are inputted into project design (Friedman, 2006). Typically, service providers' mandates for WATSAN provision focus on providing access within tight project deadlines, and inappropriate human and financial resources (Eales, 2010). This approach to tackling service delivery is typical of most municipalities, despite differences in available resources and overall performances.

In Durban, eThekwini Metro is the authority responsible for providing WATSAN services to 3.5 million people. The challenges faced by eThekwini in meeting MDG Target 10 are enormous, ranging from increasing water scarcity and water stress (DWAF, 2004) to an unnervingly rapid urbanisation rate. The worst scenarios faced by eThekwini lie in the urban areas, where an estimated 1 million people of African/Black ethnicity live in densely-populated settlements (1 437 people $/ \mathrm{km}^{2}$ ) under conditions of informal land tenure. Migration to informal settlements is driven by the need to find shelter in the proximity of job opportunities in the city (Marx and Charlton, 2003).

eThekwini's strategy to meet the MDGs entails the transformation of the city's informal settlements, either through relocation of their residents to new houses or on- site upgrading by means of basic services and infrastructures provision. To this purpose, community sanitation systems were chosen as the most appropriate solutions to swiftly serve disadvantaged communities. A CAB comprises a shared sanitation facility connected to a local sewer where the effluent is channelled. The units are characterised by separate areas for male and female users, each one with toilets or urinals, hand washbasins and showers. Provision is usually made for a storeroom and a washstand. Installation costs are incurred by the municipality, whilst users are expected take over management responsibilities. In most areas a caretaker is appointed by users to clean the toilets and liaise with the municipality on maintenance requirements. The caretaker may work on a voluntary basis or receive some compensation through a pay per use scheme.

Our assessment of CABs in Durban is explored by formulating 6 research questions (presented in Table 1), to investigate aspects of users' experience in a context of supply-driven free basic services. The responses to the research questions suggest a novel agenda and new solutions for the implementation of CABs in Durban.

\section{Methodology}

Data generation to respond to these research questions was effected via verbally administered semi-structured interviews. Three CAB schemes were selected on the basis of their operational age. Specifically, the first 2 units (Case Studies A- Clermont and B-Amaoti) had already been in use for 3 years and 1 year, respectively; a third unit (Case study C-Clermont) had just been completed at the time of investigation and

\begin{tabular}{|l|l|}
\hline \multicolumn{1}{|c|}{$\begin{array}{c}\text { Table 1 } \\
\text { Research questions }\end{array}$} \\
\hline Q 1 & What role does training play in users' ability to maintain the CAB? \\
\hline Q 2 & Is there a relationship between training received and users' satisfaction with the CAB? \\
\hline Q 3 & Is payment for maintenance and use of the CAB associated with user satisfaction? \\
\hline Q 4 & Is there a relationship between payment for using the CAB and caretaker's availability? \\
\hline Q 5 & Is there a relationship between payment for the CAB and cleanliness of the facility? \\
\hline Q 6 & How does experience of use influence perceptions of the systems? \\
\hline
\end{tabular}




\begin{tabular}{|c|c|c|c|}
\hline \multicolumn{4}{|c|}{$\begin{array}{c}\text { Table } 2 \\
\text { Descriptive statistics of sample }\end{array}$} \\
\hline Sample characteristics & $\begin{array}{c}\text { Case Study } \\
\text { A }\end{array}$ & $\begin{array}{c}\text { Case Study } \\
\text { B }\end{array}$ & $\begin{array}{c}\text { Case Study } \\
\text { C }^{*}\end{array}$ \\
\hline Estimated households & 153 & 360 & 500 \\
\hline Number of household surveyed & 29 & 57 & 50 \\
\hline Proportion of female respondents (\%) & 76 & 67 & 68 \\
\hline \multicolumn{4}{|l|}{ Ethnicity (\%) } \\
\hline Zulu & 97 & 19 & 28 \\
\hline Xhosa & & 65 & 72 \\
\hline Mpondo & & 9 & \\
\hline Others & 3 & 7 & \\
\hline \multicolumn{4}{|l|}{ Household characteristics } \\
\hline Mean household size & 6 & 4 & 4 \\
\hline Average number of children per household & 3 & 1.5 & 2 \\
\hline Proportion of household members who are in employment (\%) & 55 & 37 & 40 \\
\hline Household average monthly expenditure on food (ZAR) & 703 & 603 & 660 \\
\hline
\end{tabular}

\section{* Predicted users}

recipients had not yet used it. Within the case study area served by each technology, users were randomly selected through transect walks, generating a total of 136 valid responses. The questionnaire was specifically developed for this investigation and contained a demographic component (summarised in Table 2 ), and questions concerning use of the $\mathrm{CAB}$, its maintenance, as well as perceived benefits, challenges and acceptance.

Responses from Case Study A and Case Study B were employed to answer the first 5 research questions. Questionnaire responses were coded and processed using the Statistical Package for the Social Sciences (SPSS) V.17 software. A Chi square test was used to measure the existence of associations between those nominal variables that constitute 5 hypotheses developed from the research questions. Furthermore, to answer the final research question, experiences of use, elicited from Case Studies A and B, were compared with anticipated experiences from Case Study C.

In addition, physical inspections of the facilities were undertaken to check their operational condition. The purpose of these inspections was to validate the results of users' interviews. To obtain an unbiased picture of their condition, CABs were inspected without notifying the attending caretaker.

Three sets of results are presented in the following paragraphs: a descriptive assessment of users' experience with the technology; tests of statistically significant associations to evaluate the hypotheses derived from research questions; a comparison of experienced and anticipated benefits of $\mathrm{CAB}$ use.

\section{Results and analysis}

\section{Users' experiences of shared sanitation}

Users' experiences of the facilities in Case Study $\mathrm{A}$ and $\mathrm{B}$ are reported in Table 3 (next page). Inspection of the unit in Case Study A identified broken washing units and pipes. The block was unclean and malodorous and soap was not available to users. A facility caretaker was appointed by the community and worked on a voluntarily basis. The $\mathrm{CAB}$ was free to use for the community, with only a small contribution to be paid on a voluntary basis for maintenance. Conversely, the second CAB (Case Study B), was clean and in good working condition. A caretaker was available in loco day and night and a pay per use scheme in place. Each user paid an amount ranging from 0.5 to 1 South African Rand to use the facility.

\section{Hypotheses testing}

The aggregated data from Case Studies A and B were employed to test a set of hypotheses generated from the first 5 research questions. Table 4 reports the null hypotheses and the results of the Chi square tests.

\section{Comparison of experienced and anticipated use}

The final research question, presented in Table 1, explores how experience of using the technology affects users' perceptions of the system. To this purpose, perceptions from potential users' of a newly installed unit (Case Study C) were investigated. Descriptive statistics are reported in Table 5.

In order to assess the extent to which technology use may have influenced users' perceptions of the systems, results from Case Studies A and B were compared with the findings from Case Study C. Figure 1 illustrates a comparison between anticipated and experienced aspects of $\mathrm{CAB}$ use.

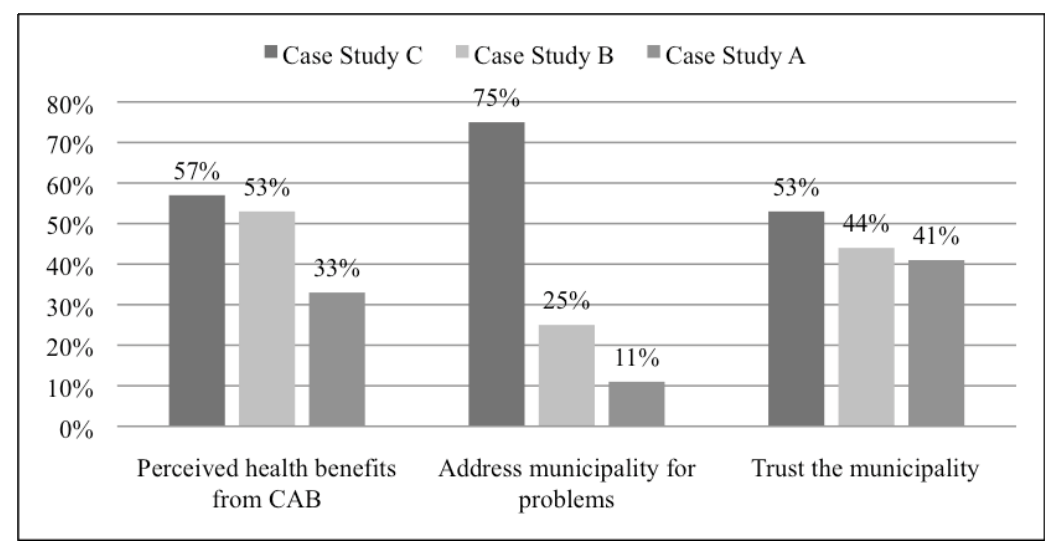

Figure 1

Comparison between experienced and anticipated use 


\begin{tabular}{|c|c|c|}
\hline \multicolumn{3}{|l|}{$\begin{array}{c}\text { Table } 3 \\
\text { Case Study A and B }\end{array}$} \\
\hline & Case Study A & Case Study B \\
\hline \multicolumn{3}{|l|}{ Use } \\
\hline Proportion of users (\%) & 93 & 44 \\
\hline Daily average use & 2.5 times & 1 time \\
\hline Proportion of respondents who received training (\%) & 22 & 40 \\
\hline Proportion of respondents who identified problems (\%) & 81.5 & 22 \\
\hline \multicolumn{3}{|l|}{ Nature of problems $(\%)$} \\
\hline Lack of safety at night & 22 & 8 \\
\hline Unclean and unpleasant environment & 29 & na* \\
\hline Malfunctioning & 16 & na \\
\hline Lack of privacy & 11.5 & na \\
\hline Unable to afford & na & 52 \\
\hline Distance from dwelling & na & 28 \\
\hline \multicolumn{3}{|l|}{ Maintenance } \\
\hline Proportion of respondents who agree on the presence of a referent for maintenance (\%) & 4 & 72 \\
\hline \multicolumn{3}{|l|}{ Attitude in case of breakage $(\%)$ : } \\
\hline Inform the caretaker & 11 & 25 \\
\hline Unaware of actions to take & 41 & 62.5 \\
\hline Use alternative means & 33 & 15.5 \\
\hline Users reporting availability of soap in the facility & 44 & 12.5 \\
\hline \multicolumn{3}{|l|}{ Acceptance } \\
\hline Proportion of satisfied users $(\%)$ & 43 & 53 \\
\hline Proportion of desirable improvement suggested (\%) & 70 & 31 \\
\hline \multicolumn{3}{|l|}{ Nature of suggested improvements (\%): } \\
\hline Regular cleaning and maintenance & 46 & 23 \\
\hline Increase of safety & 20 & 15 \\
\hline Introduce payment systems & 11 & na \\
\hline Increase of privacy & 11 & 8 \\
\hline Free to use & na & 31 \\
\hline \multicolumn{3}{|l|}{ Benefits identified, compared to previous sanitation means (\%): } \\
\hline Comfortableness & 56 & 47 \\
\hline Cleaner and healthier environment & 33 & 53 \\
\hline \multicolumn{3}{|l|}{ Advice on CAB trusted most (\%): } \\
\hline Caretaker and municipality & 41 & 44 \\
\hline Myself, neighbours or family members & 59 & 56 \\
\hline
\end{tabular}

${ }^{*} n a=$ no response given for the entry

\begin{tabular}{|l|l|l|l|}
\hline \multicolumn{5}{|c|}{ Chi square test results } \\
\hline Null hypothesis & Decision rule & Results & Conclusions \\
\hline $\begin{array}{l}\mathrm{H}_{\mathrm{o}}=\text { there is no association between training } \\
\text { received by users and satisfaction with the } \\
\text { technology }\end{array}$ & $\begin{array}{l}\mathrm{df}=2 \text { and } \alpha=0.05 \\
\text { Decision rule: } \\
\text { Reject } \mathrm{H}_{\mathrm{o}} \text { if } \chi^{2}>5.991\end{array}$ & $\begin{array}{l}\chi^{2}=10.363>5.991 \\
\text { The null hypothesis can } \\
\text { be rejected }\end{array}$ & $\begin{array}{l}\text { Those respondents who received training } \\
\text { are more satisfied with the CAB than those } \\
\text { respondents who have not received training }\end{array}$ \\
\hline $\begin{array}{l}\mathrm{H}_{\mathrm{o}}=\text { there is no association between } \\
\text { training received for the technology and } \\
\text { users' awareness of what to do in case of } \\
\text { breakdown }\end{array}$ & $\begin{array}{l}\mathrm{df}=3 \text { and } \alpha=0.05 \\
\text { Decision rule: } \\
\text { Reject } \mathrm{H}_{\mathrm{o}} \text { if } \chi^{2}>7.814\end{array}$ & $\begin{array}{l}\chi^{2}=11.133>7.814 \\
\text { The null hypothesis can } \\
\text { be rejected }\end{array}$ & $\begin{array}{l}\text { Users who receive training on CAB use are } \\
\text { better prepared to respond constructively to } \\
\text { system breakdown }\end{array}$ \\
\hline $\begin{array}{l}\mathrm{H}_{\mathrm{o}}=\text { there is no association between pay- } \\
\text { ment for the technology and users' satisfac- } \\
\text { tion with it }\end{array}$ & $\begin{array}{l}\mathrm{df}=1 \text { and } \alpha=0.05 \\
\text { Decision rule: } \\
\text { Reject } \mathrm{H}_{\mathrm{o}} \text { if } \chi^{2}>3.84\end{array}$ & $\begin{array}{l}\chi^{2}=0.493<3.84 \\
\text { The null hypothesis } \\
\text { cannot be rejected }\end{array}$ & $\begin{array}{l}\text { Users paying for the CAB are not necessarily } \\
\text { more likely to be satisfied with it }\end{array}$ \\
\hline $\begin{array}{l}\mathrm{H}_{\mathrm{o}}=\text { there is no association between pay- } \\
\text { ment for use and caretaker availability }\end{array}$ & $\begin{array}{l}\mathrm{df}=1 \text { and } \alpha=0.05 \\
\text { Decision rule: } \\
\text { Reject } \mathrm{H}_{\mathrm{o}} \text { if } \chi^{2}>3.84\end{array}$ & $\begin{array}{l}\chi^{2}=41.98>3.84 \\
\text { The null hypothesis can } \\
\text { be rejected }\end{array}$ & $\begin{array}{l}\text { Where users pay for CAB services, caretaker } \\
\text { availability is more frequent }\end{array}$ \\
\hline $\begin{array}{l}\mathrm{H}_{\mathrm{o}}=\text { there is no association between pay- } \\
\text { ment for use the technology and material } \\
\text { found in the toilets }\end{array}$ & $\begin{array}{l}\mathrm{df}=1 \text { and } \alpha=0.05 \\
\text { Decision rule: } \\
\text { Reject } \mathrm{H}_{\mathrm{o}} \text { if } \chi^{2}>3.84\end{array}$ & $\begin{array}{l}\chi^{2}=31.22>3.84 \\
\text { The null hypothesis can } \\
\text { be rejected }\end{array}$ & $\begin{array}{l}\text { Where users pay for CAB services, CAB clean- } \\
\text { liness is improved }\end{array}$ \\
\hline
\end{tabular}




\begin{tabular}{|l|c|}
\hline \multicolumn{2}{|c|}{$\begin{array}{c}\text { Cable 5 } \\
\end{array}$} \\
\hline & $\begin{array}{c}\text { Case } \\
\text { Study } \\
\text { C }^{*}\end{array}$ \\
\hline Proportion of respondents who received training (\%) & 26 \\
\hline Predicted willingness to pay (\%) & 84 \\
\hline Predicted benefits associated (\%) & \\
\hline Health and cleanliness & 57 \\
\hline Easy access to water and sanitation & 26 \\
\hline Predicted attitude in case of problems (\%) & \\
\hline Inform the caretaker or municipality & 75 \\
\hline Use alternative means & 8 \\
\hline Unsure of my behaviour & 18 \\
\hline Advice on CAB trusted most (\%) & \\
\hline Municipality or caretaker & 53 \\
\hline Myself neighbours or family members & 47 \\
\hline${ }^{*}$ Predicted perceptions given by potential users & \\
\hline
\end{tabular}

A decrease of $24 \%$ is reported in the perceptions of health benefits generated by using the shared toilets between Case Study A and Case Study C. This may be dictated by loss of enthusiasm for the systems and motivation to keep the toilets in a good status. A further variation is reported in respondents' anticipated and experienced attitudes in case of problems with the facilities. Whilst $75 \%$ of potential $\mathrm{CAB}$ users anticipated that they would report problems to the municipality, actual CAB users' willingness to address the municipality significantly decreased with experience of use (25\% and $11 \%$ ). Finally, recipients' trust in those individuals or institutions which might provide advice on the $\mathrm{CAB}$ facility was recorded by asking respondents to indicate whose advice concerning the $\mathrm{CAB}$ facility was most trusted. In Case Study A, $45 \%$ of respondents indicated that they would trust the eThekwini municipality, with a small majority $(55 \%)$ found to trust only themselves or their neighbours' opinions about CABs. Results from Case Study B reflect findings from Case Study A, in that a small majority of users (56\%) only trusted themselves or their neighbours for advice related to the CABs and only $44 \%$ trusted the municipality. In comparison, trust in the municipality among potential users' was slightly higher, (53\%), this result being further corroborated by their predicted intentions to inform the municipality in case of problems with the technology. These findings provide some evidence that experience of using CABs may influence perception of the benefits related to the facilities, as well as attitude towards and trust in service providers.

\section{Discussion}

This study highlights some of the factors which facilitate or impede implementation and acceptance of CABs in eThekwini municipal area. Similar to previous post-implementation evaluations, the investigation ascertains the importance of "nontechnical' aspects as a key influence on the process of WATSAN implementation and acceptance. Statistical results demonstrate that users' acceptance of CABs can be undermined by lack of cleanliness (as in Case Study A), or lack of affordability (as in Case Study B). These findings conform to conclusions from other studies (please reference them again!), as discussed in the introductory section. The majority of users surveyed in Durban were aware of the problems related to CABs and suggested potential improvements to the existing situation. Respondents with experience of CAB use from Case Study A and B suggested an increase in personal safety and privacy, as well as the introduction of regular cleaning and maintenance procedures. Similar findings have been highlighted by other studies (Diallo et al., 2007; Duncker et al., 2006), where convenience of use, cleanliness and privacy emerged as important issues from the investigation of acceptance of household latrines and UD toilets respectively.

Results of the Chi Square tests (Table 4) underline the importance of training in increasing users' awareness of maintenance as well as their satisfaction with the technology. Furthermore, even if, as our findings suggest, pay-per-use schemes positively influence caretaker presence and, consequently, facility cleanliness and tidiness, they do not appear to be correlated with users' satisfaction with the CAB. Although characterised by different payment schemes, neither of the CABs in Case Studies A and B met with significant levels of satisfaction. The affordability of sanitation systems is a controversial issue, particularly within a context of free service provision like South Africa, where WATSAN services are perceived as a symbol of human dignity and a legal right (Eales, 2008). Our results, however, suggest that users' financial contributions to CAB operation would provide an important incentive to caretaker availability, thus enhancing security and cleanliness, both desirable improvements suggested by users. Respondents' participation in training activities represents a further positive influence on user satisfaction with $\mathrm{CAB}$ facilities. Training proved to be correlated with respondents' satisfaction with both facilities and with proactive attitudes towards problem solving. This may relate to the role played by users' consultations and engagement in enhancing their responsibility for and acceptance of the service provided. Evidence of this argument is provided by studies on communal sanitation in India, where toilets designed, built and managed by communities attracted a high degree of acceptance from users (Burra et al., 2003).

Our findings on experienced and anticipated aspects of CAB use (Fig. 1) deserve particular attention since they corroborate results of the Chi square test (Table 4). Although Case Study A and B present different scenarios, respondents in both cases exhibit low levels of trust in the municipality's capacity to provide maintenance for the units. Furthermore, a comparison of perceptions of trust shows a discrepancy between the responses from actual and potential CAB users. Where respondents have not yet used the technology, trust in the municipality is higher when compared to that of respondents who were already using a CAB. This discrepancy may be explained by users' disillusionment with technology providers when problems are not adequately addressed. Thus, experience of use may have affected their perceptions of trust and subsequently their indifference towards the systems. This finding is also corroborated by respondents' lack of attention to problems and reporting them to the municipality (Fig. 1). In line with other studies on communal sanitation in Southern Africa (Mukheli et al., 2002), this investigation shows that after a period of use communal facilities may be perceived as mere 'open resources' for which users do not feel accountable. This may relate to the fact that eThekwini's sole responsibility for the provision of sanitation systems constitutes a poor incentive to initiate participatory approaches that would enhance users' sense of ownership.

\section{Conclusions and recommendations}

An understanding of non-technical issues is fundamental to the acceptance and sustained use of the implemented technologies. The social, cultural, economic and behavioural aspects influencing technology use should be investigated, not only at the 
planning stage but also at the early post-implementation phase, when interventions to mitigate problems are still possible. This study shows that low satisfaction levels for CABs represent a challenge to the systems' sustained use, and thus the overall success of the interventions.

Although presenting one of the most dynamic and progressive WATSAN management plans in South Africa, eThekwini's forthcoming WATSAN interventions would require significant efforts to maximise the progress towards MDG Target 10. As discussed in previous studies (Stalker Prokopy, 2005), the outcome of WATSAN projects could be significantly improved through users' involvement in decision-making. Participatory approaches should be promoted from the planning stage of interventions through inclusion of recipients in the decision-making processes. Furthermore, regular training of $\mathrm{CAB}$ users should be provided to counter the problem of frequent migrations in informal settlements. Community-based financial contribution plans could be created by linking them to micro-finance activities related to the sanitation facilities, such as locally-managed shops, health centres and recreational spaces. With users' input into project design, CABs could be transformed into central areas of the settlements where social activities occur. In the post-implementation stage, mechanisms for monitoring $\mathrm{CAB}$ performance should be in place. Users' motivation and responsibility could be kept high through the use of post-implementation awards for the best performing facility, as successfully implemented in East Asia (Evans and Trémolet, 2010).

A participatory implementation of $\mathrm{CABs}$ is a challenging endeavour in a context of supply-driven services,

which requires mutual engagement from both providers and recipients. This entails recognition that recipients constitute an essential resource, providing inputs to the design and management of the facilities through appropriate participation platforms (Friedman, 2006). To achieve this goal, building capacities within the municipality of Durban is fundamental. Capacity building would not only provide the necessary knowledge management skills, but also generate willingness to adopt demanddriven interventions. Finally, development of novel strategies that take into account associated delays in service supply and software costs in delivery would be required. Ultimately, this mutual effort could translate into considerable gains for all parties, expressed in terms of users' acceptance and thus sustained use of the facilities.

\section{Acknowledgements}

The authors are grateful to the two anonymous reviewers whose comments made the final version of this paper possible. This study was made possible thanks to the support of eThekwini Metro and the University of KwaZulu-Natal. Particularly, the authors would like to thank eThekwini Health and Water and Sanitation Departments for their support and knowledge shared. Furthermore, we would like to thank Dr Zoe Wilson for her precious advice, as well as Sandile Mbatha and Nhlanhla Mgeba for their help during the fieldwork.

\section{References}

BRESLIN ED (2004) Strengthening the Demand-Responsive approach: Learning form program experience in Niassa province, Mozambique. In: ADB-Asian Development Bank (2004) Water and Poverty: the Realities. Experiences from the Field. Asian Development Bank, Manila, Philippines. p. 10-16.

BURRA S, PATEL S AND KERR T (2003) Community-designed, built and managed toilet blocks in Indian cities. Environ. Urban. 15 (2) 11-32.
DWAF (DEPARTMENT OF WATER AFFAIRS AND FORESTRY, SOUTH AFRICA) (2004) National Water Resource Strategy. First Edition. Department of Water Affairs and Forestry, Pretoria, South Africa.

DWAF (DEPARTMENT OF WATER AFFAIRS AND FORESTRY, SOUTH AFRICA) (1994) Water Supply and Sanitation Policy. White Paper. Department of Water Affairs and Forestry, Pretoria, South Africa.

DIALLO MO, HOPKINS DR, KANE MS, NIANDOU S, AMADOU A, KADRI B, AMZA A, EMERSON PM, ZINGESER JA (2007)

Household latrine use, maintenance and acceptability in rural Zinder, Niger. Int. J. Environ. Health Res. 17 (6) 443-452.

DUNCKER LC, MATSEBE GN and AUSTIN LM (2006) Use and acceptance of Urine-Diversion sanitation systems in South Africa. Vol. 2. WRC Report No. 1439/2/06. Water Research Commission, Pretoria.

EALES K (2010) Some challenges for DEWATS approaches in South Africa. Proc. IWA Decentralized Wastewater Treatment Solutions in Developing Countries, 23-26 March 2010, Surabaya, Indonesia.

EALES K (2008) Rethinking sanitation improvement for poor households in urban South Africa. Paper presented at the IRC SYMPOSIUM: Sanitation for the urban poor partnerships and governance, 18-21 November 2008, Delft, The Netherlands.

EVANS B and TRÉMOLET S (2010) Targeting the poor-facilities and improved sanitation. In: Köhn D and Pfeiffer V (eds.) Financing Sanitation: Improving Hygiene Awareness and Sanitation. KWF Water Symposium, IWA Publishing, London, UK. 19-31.

FRIEDMAN S (2006) Participatory governance and citizen action in post-apartheid South Africa. Discussion Paper DP/164/2006, International Institute for Labour Studies, Geneva, Switzerland.

JEFFREY P and SEATON RAF (2004) A conceptual model of receptivity applied to the design and deployment of water policy mechanisms. Environ. Sci. 1 (3) 277-300.

KIHATO C and SCHMITZ T (2002) Enhancing policy implementation: lessons from the water sector. Research Report 95, Social Policy Series, Centre for Policy Studies, Johannesburg. South Africa.

LINSTONE H (1981) The multiple perspective concept with application to technology assessment and other decision areas. Technol. Forecast. 20 275-325.

LÜBKEN M, WICHERN M, BISCHOF F, PRECHTL S and HORN $\mathrm{H}$ (2007) Development of an empirical mathematical model for describing and optimizing the hygiene potential of a thermophilic anaerobic bioreactor treating faeces. Water Sci. Technol. 55 (7) 95-102.

MARX C and CHARLTON S (2003) Urban slums report: The case of Durban, South Africa. In: UN-Habitat (2003) Global Report on Human Settlements 2003, The Challenge of Slums. Earthscan, London, UK. 195-228.

MUKHELI A, MOSUOYE G and SWATUK LA (2002) Is the Pungwe water supply project a solution to accessibility and sanitation problems to the households of Sakubva, Zimbabwe? Phys. Chem. Earth 27 723-732.

RODGERS A, AJONO L, GYAPONG J, HAGAN M and EMERSON P (2007) Characteristics of latrine promotion participants and nonparticipants: Inspection of latrines; and perceptions of household latrines in Northern Ghana. Trop. Med. Int. Health 12 (6) 772-782.

SIMMS VM, MAKALO P, BAILEY RL and EMERSON PM (2005) Sustainability and acceptability of latrine provision in the Gambia. Trans. R. Soc. Trop. Med. Hyg. 99 631-637.

STALKER PROKOPY L (2005) The relationship between participation and project outcomes: evidence from rural water supply projects in India. World Dev. 33 (11) 1801-1819.

UN (UNITED NATIONS) (2005) South Africa: Millennium Development Goals Country Report. United Nations, New York, USA.

WHO (WORLD HEALTH ORGANIZATION) and UNICEF (UNITED NATIONS CHILDREN'S FUND) (2008) Progress on Drinking Water and Sanitation: Special Focus on Sanitation. Joint Monitoring Programme for Water Supply and Sanitation. UNICEF, New York, USA and WHO, Geneva, Switzerland.

YOUNGER PL (2007) Pro-poor water technologies working both ways: lessons form a two-way, south-north interchange. Geoforum 38 (5) 828-840. 